\title{
Review
}

\section{Outpatient Total Hip Arthroplasty: A Meta-Analysis}

\author{
Filippo Migliorini 1,*D, Lucio Cipollaro ${ }^{2,3}$, Francesco Cuozzo ${ }^{2}$, Francesco Oliva ${ }^{2,3}$, Andrea Valerio Marino ${ }^{2}$ \\ and Nicola Maffulli ${ }^{2,4,5}$ (D)
}

1 Department of Orthopaedic and Trauma Surgery, RWTH University Hospital Aachen, 52074 Aachen, Germany

2 Department of Musculoskeletal Disorders, Faculty of Medicine and Surgery, University of Salerno, 84084 Baronissi, Italy; 1.cipollaro87@gmail.com (L.C.); fra.cuoz@gmail.com (F.C.); olivafrancesco@hotmail.com (F.O.); andreavmarino1@gmail.com (A.V.M.); n.maffulli@qmul.ac.uk (N.M.)

3 Clinica Ortopedica, Ospedale San Giovanni di Dio e Ruggi d'Aragona, 84131 Salerno, Italy

4 Centre for Sports and Exercise Medicine, Barts and The London School of Medicine and Dentistry, Mile End Hospital, 275 Bancroft Road, London E1 4DG, UK

5 School of Pharmacy and Biotechnology, Keele University School of Medicine, Thornburrow Drive, Stoke-on-Trent ST4 7QB, UK

* Correspondence: migliorini.md@gmail.com; Tel.: +49-0241-80-35529

Citation: Migliorini, F.; Cipollaro, L.; Cuozzo, F.; Oliva, F.; Marino, A.V.; Maffulli, N. Outpatient Total Hip Arthroplasty: A Meta-Analysis. Appl. Sci. 2021, 11, 6853. https://doi.org/ 10.3390/app11156853

Academic Editor: Arnd Steinbrück

Received: 4 July 2021

Accepted: 23 July 2021

Published: 26 July 2021

Publisher's Note: MDPI stays neutral with regard to jurisdictional claims in published maps and institutional affiliations.

Copyright: (c) 2021 by the authors. Licensee MDPI, Basel, Switzerland. This article is an open access article distributed under the terms and conditions of the Creative Commons Attribution (CC BY) license (https:// creativecommons.org/licenses/by/ $4.0 /)$.

\begin{abstract}
Introduction: Outpatient total hip arthroplasty (THA) is increasingly popular. This meta-analysis investigated the potential advantages of outpatient regimes for THA. Methods: This study followed the PRISMA guidelines. PubMed, Web of Science, Google Scholar, Embase, and Scopus databases were accessed in June 2021. All clinical studies investigating outpatient THA were considered. The outcomes of interest were pain, infection, mortality, revision, dislocation, readmission rates, and deep vein thrombosis (DVT). Results: Data from 102,839 patients were included. A total of $52 \%$ (153,168 of 102,839 patients) were women. The mean age of patients was $62.6 \pm 4.6$ years, the mean BMI was $29.1 \pm 1.8 \mathrm{~kg} / \mathrm{m}^{2}$. Good comparability was found in age, BMI, and gender $(p>0.1)$. No difference was found in pain $(p=0.4)$, infections $(p=0.9)$, mortality $(p=0.9)$, rate of revision $(p=0.1)$, dislocation $(p=0.9)$, and readmission $(p=0.8)$. The outpatient group demonstrated a greater rate of DVT (OR 3.57; 95\% CI 2.47 to 5.18; $p<0.0001$ ). Conclusions: In selected patients, outpatient THA can be performed safely with optimal outcomes comparable with inpatient THA. Clear and comprehensive pre-operative planning should involve a multi-disciplinary group composed of orthopaedic surgeons, anaesthesia and rehabilitation specialists, and physiotherapists. Each centre performing outpatient THA should implement continuous homecoming welfare activity, to supervise physiotherapy and monitor anticoagulant therapy.
\end{abstract}

Keywords: total hip arthroplasty; inpatients; outpatients

\section{Introduction}

Total hip arthroplasty (THA) is the treatment choice for advanced hip osteoarthritis. THA has typically been considered as an inpatient procedure [1,2]. Postoperative care after THA has evolved during the past 40 years [3]. Initially, patients undergoing THA could have been hospitalized even longer than two weeks and spend further weeks in a rehabilitation centre [4]. Weightbearing was limited and mobilisation delayed [4]. Postoperative protocols have evolved to decrease costs and allow faster discharge and return to previous daily living activities [5-9]. Improvement in pain management and bleeding control, regional anaesthesia, direct postoperative full weightbearing, and fast track concepts in hospitalization and rehabilitation have been introduced [1,5,10-12]. Long hospitalisation has been associated with a higher rate of complications [13,14]. However, outpatient THA remains reserved to a few selected patients: less than $1 \%$ of THAs in the United States are performed as outpatient procedures [15-17]. A patient's selection is mandatory. The current exclusion criteria for outpatient THA includes heart and vascular 
diseases, a history of transient ischemic attack, chronic obstructive pulmonary disease, untreated obstructive sleep apnoea, obesity, haemoglobin $<130 \mathrm{~g} / \mathrm{L}$, diabetes mellitus, endstage hepatic and/or renal disease, history of delirium or dementia, solid organ transplant, and advanced neoplasm [18,19].

Several clinical studies comparing outpatient versus inpatient THA ( $>2$ days) are available $[1,11,13,14,17,20-30]$. However, most of them have been recently published, and, therefore, have not yet been considered in previous systematic reviews and metaanalyses. This meta-analysis compared outpatient versus inpatient THA ( $>2$ days) in terms of symptoms, rates of infection, mortality, revision, dislocation, readmission, and deep vein thrombosis (DVT). We hypothesised that, for selected patients, outpatient THA provides comparable results to inpatient procedures.

\section{Material and Methods}

\subsection{Search Strategy}

This systematic review was conducted according to the Preferred Reporting Items for Systematic Reviews and Meta-Analyses: the 2020 PRISMA statement [31]. The PICO algorithm guided the initial search:

- P (Population): end stage hip osteoarthritis;

- I (Intervention): outpatient THA;

- C (Comparison): inpatient ( $>2$ days) THA;

- O (Outcomes): pain, infections, mortality, revisions, dislocations, readmissions, DVT.

\subsection{Data Source and Extraction}

The literature search was performed by two authors (F.M. and L.C.) independently. In June 2021, the main databases were accessed: PubMed, EMBASE, Google Scholar, and Scopus. The following keywords were used in combination: one day, day surgery, outpatient, inpatient, fast track, arthroplasty, hip, prosthesis, replacement, readmission, revision, stay, hospitalization, deep vein thrombosis, complications, failure. The resulting articles were examined and, if of interest, the full text version was accessed. The bibliographies were also screened for inclusion of further articles. Any disagreements were discussed and settled by consensus.

\subsection{Eligibility Criteria}

All clinical trials comparing one outpatient versus inpatient ( $>2$ days) THA were considered. Only study comparative investigations published in peer reviewed journals were considered. According to the authors' language capabilities, articles in English, German, Italian, French, and Spanish were eligible. According to Oxford Centre of Evidence-Based Medicine [32], levels I to IV of evidence were considered. Reviews, opinions, letters, and editorials were not considered. Animals, biomechanics, computational, and cadaveric studies were not eligible. Only articles which reported quantitative data with regard to symptoms and complications were eligible. Studies which enhanced THA with cell therapies or with experimental surgical or rehabilitative protocols were not suitable, nor where those experimenting new implants designs.

\subsection{Selection and Data Collection}

Two authors (F.M. and L.C.) independently performed the database search. All the resulting titles were screened and, if suitable, the abstract was accessed. The full text of abstracts matching the topic were accessed. A cross reference of the bibliography of full-text articles were also screened for inclusion. Disagreements were debated and the final decision was decided by a third author (NM).

\subsection{Data Items}

Two authors (F.M. and L.C.) independently performed data extraction. The following data were extracted: generalities (author, year, journal, type of study) and patient baseline 
demographic information (number of samples, sex, mean age and BMI, length of the hospital stay) were collected. The outcomes of interest were: pain, rates of infection, mortality, revision, dislocation, readmission, and deep vein thrombosis (DVT).

\subsection{Methodology Quality Assessment}

The Coleman Methodology Score (CMS) was used to evaluate the quality of the methodology of each investigation. The CMS is widely used to evaluate the methodological quality of scientific articles for systematic reviews and meta-analyses [33]. The CMS evaluates the study size, length of the follow-up, type of study, diagnosis description, surgical technique, and rehabilitation. Additionally, outcome criteria assessment, procedures for assessing outcomes, and the subject selection process were also evaluated. The CMS rated articles with values between 0 (poor) and 100 (excellent). A mean value greater than 60 points was considered satisfactory.

\subsection{Statistical Analysis}

Statistical analyses were performed by the main author (F.M.). These meta-analyses were performed using the Review Manager Software 5.3 (The Nordic Cochrane Collaboration, Copenhagen). Binary data were evaluated through a Mantel-Haenszel analysis, with odd ratio (OR) effect measure. The comparisons were performed with a fixed model effect as set up. Heterogeneity was assessed through the $\chi^{2}$ and Higgins- $\mathrm{I}^{2}$ test. If $\chi^{2}<0.05$ and If $\mathrm{I}^{2}$ test $>50 \%$, high heterogeneity was detected. In cases of heterogeneity, a random model effect was used. The confidence intervals (CI) were set at $95 \%$ in all comparisons. The overall effect was considered statistically significant if $p<0.05$. The funnel plot of the most reported outcome was performed to assess the risk of publication bias. Egger's linear regression was performed through the STATA/MP Software version 16 (StataCorp, College Station, TX, USA) to assess funnel plot asymmetry, with values of $p<0.05$ indicating statistically significant asymmetry.

\section{Results}

\subsection{Search Result}

A total of 147 articles were identified during the initial search. Of these, 35 duplicates were excluded. An additional 72 articles were excluded because of the following reasons: not comparative study $(n=31)$, type of study $(n=35)$, uncertain methodology or results $(n=5)$, and language limitation $(n=1)$. An additional 24 articles were excluded as they lacked quantitative data under the outcomes of interest. This left 16 studies for inclusion (Figure 1).

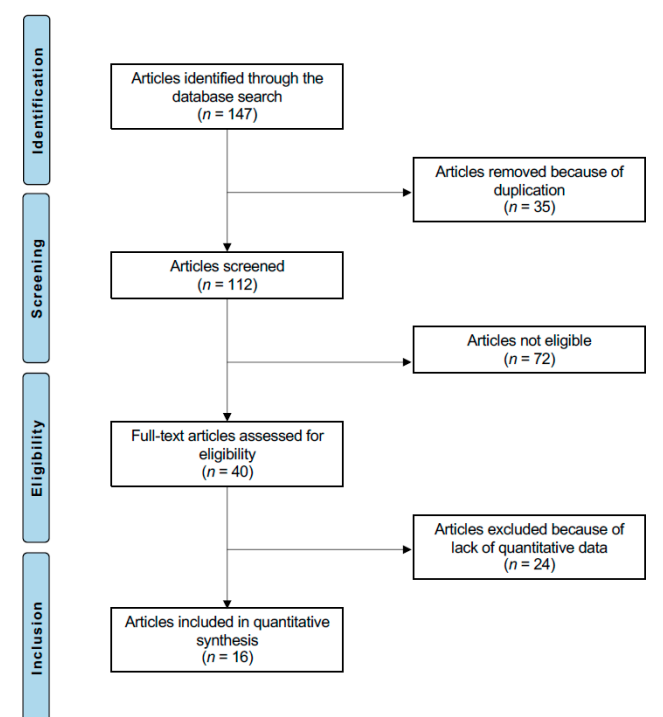

Figure 1. Literature search flow chart. 


\subsection{Methodological Quality Assessment}

The study size and the length of the follow-up were reliable in most of considered articles. The surgical technique, diagnosis, and rehabilitation protocols were generally well described. The retrospective design of $50 \%(8 / 16)$ of the included studies represented an important limitation highlighted by the CMS. Outcome measures and the assessment timing were often well defined, providing moderate reliability. Concluding, CMS resulted in $72.4 \pm 5.5$, attesting to the present study a good quality of the methodological assessment (Table 1).

Table 1. Methodological quality assessment.

\begin{tabular}{lccc}
\hline \multicolumn{1}{c}{ Endpoint } & Mean & SD & Range \\
\hline Part A: Only one score to be given for each of the 7 sections & & & 4 to 10 \\
Study size: number of patients & 9.43 & 1.63 & 0 to 4 \\
Mean follow-up & 0.25 & 1.0 & 0 to 10 \\
Surgical approach & 8.25 & 2.64 & 0 to 15 \\
Type of study & 5.31 & 5.61 & 0 to 5 \\
Description of diagnosis & 4.37 & 1.70 & 0 to 10 \\
Descriptions of surgical technique & 6.94 & 3.48 & 0 to 5 \\
Description of postoperative rehabilitation & 3.12 & 2.5 & 2 to 3 \\
Part B: Scores may be given for each option in each of the 3 sections & 2.5 & 0.5 & 3 to 5 \\
Outcome criteria & 3.74 & 0.84 & 0 to 5 \\
Procedure of assessing outcomes & 4.83 & 0.88 & \\
Description of subject selection process & & & \\
\hline
\end{tabular}

\subsection{Risk of Publication Bias}

The funnel plot of most reported outcome was performed to assess the risk of publication bias (Figure 2). The graph evidenced minimal asymmetry. Most of effects points were located in the pyramidal shape. Moreover, the Egger's test evidenced no statistically significant asymmetry $(p=0.08)$. Concluding, the funnel plot indicated a low to moderate risk of publication bias.

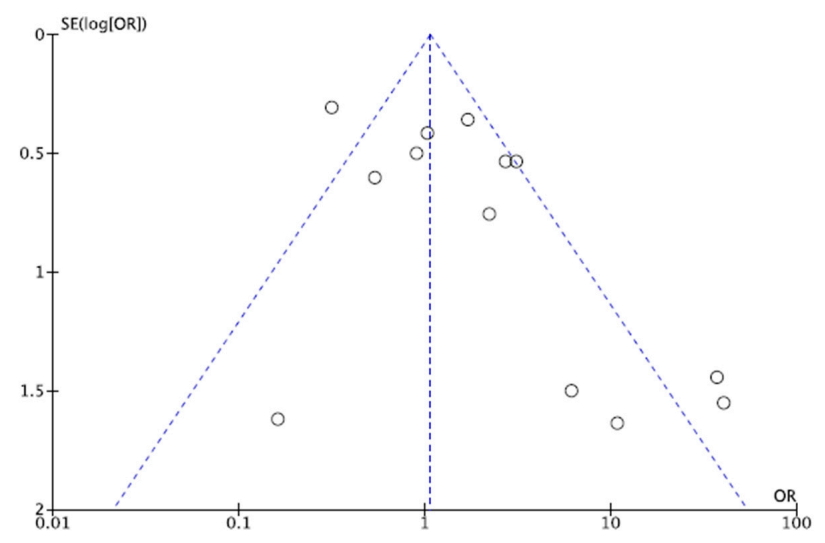

Figure 2. Funnel plot.

\subsection{Patient Demographic}

Data from 102,839 patients were included. A total of 52\% (53,168 of 102,839 patients) were women. The mean age of patients was $62.6 \pm 4.6$ years, and the mean BMI was $29.1 \pm 1.8 \mathrm{~kg} / \mathrm{m}^{2}$. A good between-groups comparability was found in age, BMI, and the female:male ratio $(p>0.1)$. An overview of the included studies is shown in Table 2.

\subsection{Outcomes of Interest}

No difference was found in pain $(p=0.4)$, infections $(p=0.9)$, mortality $(p=0.9)$, revision $(p=0.1)$, dislocation $(p=0.9)$, and readmission $(p=0.8)$ between the two groups. The outpatient group demonstrated a greater rate of DVT (OR 3.57; 95\% CI 2.47 to 5.18; $p<0.0001)$. These results are shown in greater detail in Figure 3. 
Table 2. Studies generalities and patient demographics (CMS: Coleman Methodology Score).

\begin{tabular}{|c|c|c|c|c|c|c|c|c|}
\hline Author et al., Year & Journal & Study Design & CMS & Length of Stay & Patients $(n)$ & Age & Female (\%) & BMI $\left(\mathrm{kg} / \mathrm{m}^{2}\right)$ \\
\hline Aynardi et al., 2014 [11] & HSS J. & Prospective & 80 & $\begin{array}{l}1 \text { Day } \\
>2 \text { Days }\end{array}$ & $\begin{array}{c}119 \\
78\end{array}$ & $\begin{array}{l}59.0 \\
61.5\end{array}$ & $\begin{array}{l}40 \\
67\end{array}$ & $\begin{array}{l}28.1 \\
33.2\end{array}$ \\
\hline Bertin et al., 2005 [1] & Clin. Orthop. Relat. Res. & Retrospective & 69 & $\begin{array}{l}1 \text { Day } \\
>2 \text { Days }\end{array}$ & $\begin{array}{l}10 \\
10\end{array}$ & $\begin{array}{l}62.0 \\
63.0\end{array}$ & $\begin{array}{l}40 \\
50\end{array}$ & $\begin{array}{l}30.0 \\
29.6\end{array}$ \\
\hline Carey et al., 2019 [20] & J. Arthroplast. & Retrospective & 70 & $\begin{array}{l}1 \text { Day } \\
>2 \text { Days }\end{array}$ & $\begin{array}{c}623 \\
1869\end{array}$ & $\begin{array}{l}61.0 \\
61.0\end{array}$ & & \\
\hline Crampet et al., 2019 [21] & Orthop. Traumatol. Surg. Res. & Retrospective & 72 & $\begin{array}{l}1 \text { Day } \\
>2 \text { Days }\end{array}$ & $\begin{array}{l}50 \\
77\end{array}$ & $\begin{array}{l}62.7 \\
70.5\end{array}$ & $\begin{array}{l}44 \\
81\end{array}$ & $\begin{array}{l}25.6 \\
26.5\end{array}$ \\
\hline Goyal et al., 2017 [22] & Clin. Orthop. Relat. Res. & $\mathrm{RCT}$ & 85 & $\begin{array}{l}1 \text { Day } \\
>2 \text { Days }\end{array}$ & $\begin{array}{l}112 \\
108\end{array}$ & $\begin{array}{l}59.8 \\
60.2\end{array}$ & $\begin{array}{l}47 \\
46\end{array}$ & $\begin{array}{l}27.6 \\
28.3\end{array}$ \\
\hline Greenky et al., 2019 [23] & J. Arthroplast. & Retrospective & 75 & $\begin{array}{l}1 \text { Day } \\
>2 \text { Days }\end{array}$ & $\begin{array}{c}310 \\
28,408\end{array}$ & $\begin{array}{l}71.4 \\
73.8\end{array}$ & & $\begin{array}{l}29.6 \\
29.2\end{array}$ \\
\hline Gromov et al., 2019 [17] & Acta Orthop. & Prospective & 75 & $\begin{array}{l}1 \text { Day } \\
>2 \text { Days }\end{array}$ & $\begin{array}{c}70 \\
339\end{array}$ & $\begin{array}{l}61.0 \\
62.0\end{array}$ & $\begin{array}{l}41 \\
43\end{array}$ & $\begin{array}{l}28.0 \\
28.0\end{array}$ \\
\hline Kelly et al., 2018 [24] & J. Arthroplast. & Prospective & 74 & $\begin{array}{l}1 \text { Day } \\
>2 \text { Days }\end{array}$ & $\begin{array}{l}23 \\
28\end{array}$ & $\begin{array}{l}59.2 \\
64.1\end{array}$ & $\begin{array}{l}58 \\
28\end{array}$ & $\begin{array}{l}30.4 \\
32.7\end{array}$ \\
\hline Krenk et al., 2014 [25] & Anesth. Analg. & Prospective & 67 & $\begin{array}{c}1 \text { Day } \\
>2 \text { Days }\end{array}$ & $\begin{array}{l}220 \\
220\end{array}$ & $\begin{array}{l}72.0 \\
68.0\end{array}$ & $\begin{array}{c}9 \\
91\end{array}$ & \\
\hline Lovecchio et al., 2016 [13] & J. Arthroplast. & Prospective & 77 & $\begin{array}{l}1 \text { Day } \\
\text { >2 Days }\end{array}$ & $\begin{array}{l}183 \\
585\end{array}$ & $\begin{array}{l}64.0 \\
65.0\end{array}$ & $\begin{array}{l}56 \\
55\end{array}$ & $\begin{array}{l}30.0 \\
29.0\end{array}$ \\
\hline Nelson 2016 et al., 2016 [26] & J. Arthroplast. & Retrospective & 70 & $\begin{array}{l}1 \text { Day } \\
>2 \text { Days }\end{array}$ & $\begin{array}{c}420 \\
63,424\end{array}$ & $\begin{array}{l}62.0 \\
65.0\end{array}$ & $\begin{array}{l}47 \\
55\end{array}$ & $\begin{array}{l}28.0 \\
29.0\end{array}$ \\
\hline Otero et al., 2016 [14] & J. Arthroplast. & Prospective & 70 & $\begin{array}{c}1 \text { Day } \\
>2 \text { Days }\end{array}$ & $\begin{array}{c}249 \\
1940 \\
\end{array}$ & $\begin{array}{l}62.6 \\
59.9 \\
\end{array}$ & $\begin{array}{l}50 \\
38 \\
\end{array}$ & $\begin{array}{l}29.4 \\
29.4 \\
\end{array}$ \\
\hline Richards et al., 2018 [27] & J. Arthroplast. & Prospective & 68 & $\begin{array}{l}1 \text { Day } \\
>2 \text { Days }\end{array}$ & $\begin{array}{l}136 \\
396\end{array}$ & $\begin{array}{l}53.2 \\
55.4\end{array}$ & $\begin{array}{l}71 \\
54\end{array}$ & $\begin{array}{l}27.5 \\
29.6\end{array}$ \\
\hline Tedder et al., 2018 [28] & J. Foot Ankle Surg. & Retrospective & 75 & $\begin{array}{l}1 \text { Day } \\
>2 \text { Days }\end{array}$ & $\begin{array}{c}66 \\
535\end{array}$ & $\begin{array}{l}58.9 \\
64.0\end{array}$ & $\begin{array}{l}58 \\
49\end{array}$ & $\begin{array}{l}29.0 \\
30.0\end{array}$ \\
\hline Weiser et al., 2018 [29] & J. Arthroplast. & Retrospective & 70 & $\begin{array}{l}1 \text { Day } \\
>2 \text { Days }\end{array}$ & $\begin{array}{c}164 \\
1315\end{array}$ & $\begin{array}{l}56.8 \\
58.0\end{array}$ & $\begin{array}{l}52 \\
57 \\
\end{array}$ & $\begin{array}{l}26.9 \\
28.2\end{array}$ \\
\hline Ziemba-Davis et al., 2019 [30] & J. Arthroplast. & Retrospective & 62 & $\begin{array}{l}1 \text { Day } \\
\text { >2 Days }\end{array}$ & $\begin{array}{l}164 \\
588\end{array}$ & $\begin{array}{l}63.4 \\
63.0\end{array}$ & $\begin{array}{l}61 \\
60\end{array}$ & $\begin{array}{l}32.6 \\
30.1\end{array}$ \\
\hline
\end{tabular}




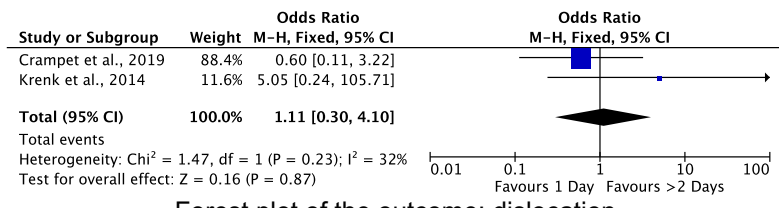

Forest plot of the outcome: dislocation

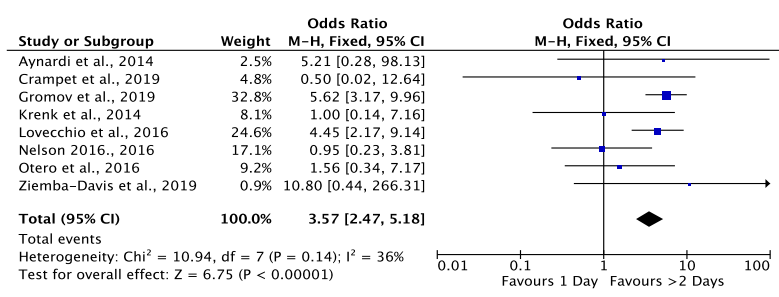

Forest plot of the outcome: deep vein thrombosis

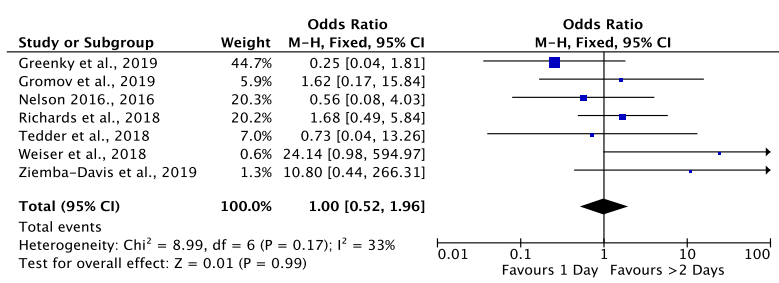

Forest plot of the outcome: infections

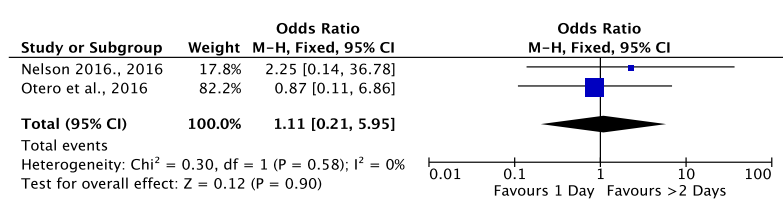

Forest plot of the outcome: mortality

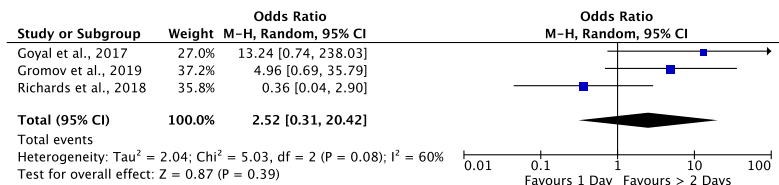

Forest plot of the outcome: pain

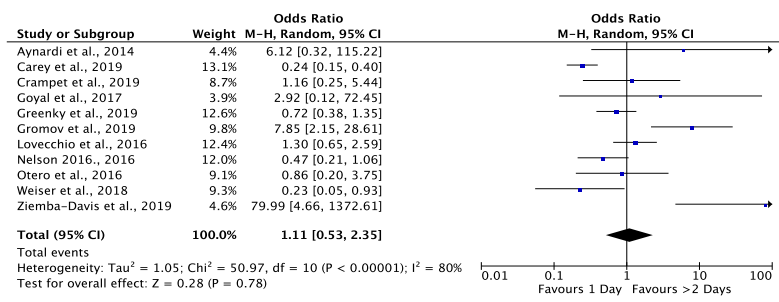

Forest plot of the outcome: readmission

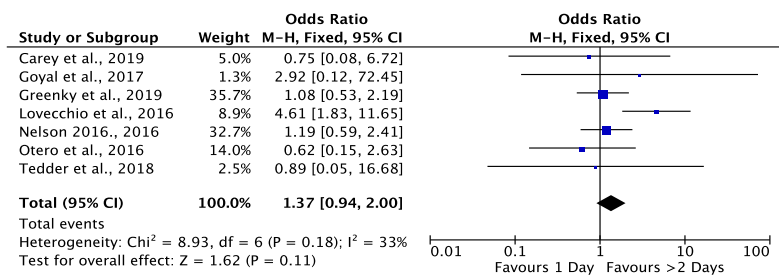

Forest plot of the outcome: revision

Figure 3. Forest plots. 


\section{Discussion}

Results from the present meta-analysis encourage outpatient THA. Indeed, according to the main findings of the present study, the outcome of outpatient THA was similar to the procedure with longer hospitalisation. Indeed, no difference was found in pain, infections, mortality, revision, dislocation, and readmission rates between the two groups. A statistically significant greater risk of DVT in patients following outpatient THA was evidenced. This may result from the reduced care by the health care personnel once discharged [34]. According to this evidence, each centre performing outpatient THA should implement continuous homecoming welfare activity, to supervise physiotherapy and the monitoring anticoagulant therapy [14]. Comprehensive multidisciplinary cares include the orthopaedic surgeon, nurses, anaesthesiologists, and physical and occupational therapists. To support homestay recovery, the primary caregiver may help to restore and expedite patient self-care and daily living activities and to reduce mobility [35,36]. A recent systematic review evidenced a higher rate of within 60 days DVT in outpatient THA patients (outpatient 1.28\% versus inpatient $1.21 \%$ ) [37]. This is the only systematic review which reported a higher rate of DVT in outpatient THA patients. Expanding the literature search to articles which evaluated outpatient total joint arthroplasty, DVT-related risk rate did not significantly differ from outpatient and inpatient TJA groups [5,16,38,39]. Results from the present study indicated that outpatient THA, in appropriately selected populations, may faster restore the patient quality of life without affecting the clinical outcome. Moreover, outpatient THA significantly reduces health-care costs $[1,11,38,40]$. For a successful outpatient THA, proper patient selection is mandatory [38,41-45]. Comorbidities may negatively interfere with the surgical success, being associated with a greater rate of intraoperative and postoperative complications [46]. Suitable patients should be relatively young and healthy, with a solid social support and good performance status [47]. Meneghini et al. [48] developed the Outpatient Arthroplasty Risk Assessment (OARA) to identify which patients may reliably undergo outpatient arthroplasty. The OARA allows to generate risk categories stratifying patients in nine separate comorbidity layers. On the other extreme, Otero et al. [14] stated that patients with comorbidities can still be safely discharged as outpatient THA, given the pivotal importance of the solid social support and networking after discharge at homestay. Optimal pain management protocols should be adopted to be able to undertake outpatients THA in a safe and effective fashion [38]. Postoperative pain management and appropriate patients care are essential factors for outpatient THA pain control at homestay, especially during the first postoperative days [22]. Outpatient THA can be successfully achieved thanks to the advancements in pain management, regional anaesthesia, focused rehabilitation, surgical progresses, and the patient selection process [27]. The management of immediate postoperative complications is critical. Anaesthetic-related side effects such as nausea, hypotension, and urinary retention are common and should be promptly managed $[22,26]$. The readmission rate is important to evaluate the efficacy of outpatient THA [49,50]. Lovecchio et al. [13], in 1968, found that the most common causes for THA readmission were bleeding and DVT [13]. Springer et al. [51] evidenced increased readmission rates in outpatient THA $(11.7 \%$ vs. $6.6 \%)$, mostly for pain, wound complications, and adverse reaction to pain medication. Greenky et al. [23] found a lower rate of complication and readmission within 30-days postoperatively in favour of outpatient THA. In a recent review, Shapira et al. [52] evidenced a within 3 months outpatient THA readmission rate of $0.34 \%$. In this regard, previously published readmission rates for inpatient THA scored higher $[17,53,54]$. Those results reinforce the benefits for patients and the health-care system of performing outpatient THA. Regarding the revision rate, we found no difference in both protocols. Evidence with regard to the revision rate was unclear and studies reported controversial results [20]; while some evidence demonstrated a greater revision rate in outpatient THA [22], other authors found a greater rate in the longer hospitalisation cohort [14,23,26], and another still found no difference [13].

This study has limitations. The retrospective design by most of the included studies certainly represented a potential source of selection bias. Moreover, there was an over- 
all lack of blinding and the length of the follow-up was not adequate by most studies. Given the lack of quantitative data, subgroup analyses according to the surgical access and exposure, stem length, and implant design were not possible to be analysed separately. However, previous meta-analyses have demonstrated that many of those factors do not impact significantly on the outcome of THA procedures [55-60]. Different surgical approaches, as well as different surgical exposures, do not significantly impact the outcomes of THA $[61,62]$. Comparable results were reached evaluating implant stem length-related outcomes, and no difference in terms of complications and revision rates was found $[60,63]$. The heterogeneity between groups with regard to baseline characteristics represents another limitation. Indeed, outpatient THA patients are healthier and younger than their inpatient counterparts. That is not surprising, given the strict inclusion criteria used to enrol outpatient arthroplasty candidates. A patient's age is a known risk factor for perioperative complications in THA [55]. Another study limitation concerns the lack of data regarding information about functional outcomes and rehabilitation programs. Given the heterogeneity of data and protocols, it was not possible to compare outpatient THA versus fast-track or other traditional inpatient lengths of hospital stay. Therefore, in light of these limitations, data from the present study must be considered with caution.

\section{Conclusions}

In selected patients, outpatient THA can be performed safely with optimal outcomes comparable with the inpatient group. Clear and comprehensive pre-operative planning should involve a multi-disciplinary group composed of orthopaedic surgeons, anaesthesia and rehabilitation specialists, and physiotherapists. Each centre performing outpatient THA should implement continuous homecoming welfare activity, to supervise physiotherapy and monitor anticoagulant therapy.

Author Contributions: F.C.: writing; F.O.: supervision; A.V.M.: writing; N.M.: final approval; F.M.: wiritng, data source and extraction; selection and data collection, data items, statistical analyses; L.C.: data source and extraction; selection and data collection, data items, methodology quality assessment. All authors have read and agreed to the published version of the manuscript.

Funding: This research received no external funding.

Institutional Review Board Statement: Not applicable.

Informed Consent Statement: Not applicable.

Data Availability Statement: Data is contained within the article.

Conflicts of Interest: The authors declare no conflict of interest.

\section{References}

1. Bertin, K.C. Minimally Invasive Outpatient Total Hip Arthroplasty: A Financial Analysis. Clin. Orthop. Relat. Res. 2005, 435, 154-163. [CrossRef] [PubMed]

2. Paredes, O.; Nunez, R.; Klaber, I. Successful Initial Experience with a Novel Outpatient Total Hip Arthroplasty Program in a Public Health System in Chile. Int. Orthop. 2018, 42, 1783-1787. [CrossRef]

3. Mears, D.C.; Mears, S.C.; Chelly, J.E.; Dai, F.; Vulakovich, K.L. THA with a Minimally Invasive Technique, Multi-Modal Anesthesia, and Home Rehabilitation: Factors Associated with Early Discharge? Clin. Orthop. Relat. Res. 2009, 467, 1412-1417. [CrossRef] [PubMed]

4. Klein, G.R.; Posner, J.M.; Levine, H.B.; Hartzband, M.A. Same Day Total Hip Arthroplasty Performed at an Ambulatory Surgical Center: 90-Day Complication Rate on 549 Patients. J. Arthroplast. 2017, 32, 1103-1106. [CrossRef] [PubMed]

5. Berger, R.A.; Jacobs, J.J.; Meneghini, R.M.; Della Valle, C.; Paprosky, W.; Rosenberg, A.G. Rapid Rehabilitation and Recovery with Minimally Invasive Total Hip Arthroplasty. Clin. Orthop. Relat. Res. 2004, 429, 239-247. [CrossRef] [PubMed]

6. Husted, H.; Holm, G.; Jacobsen, S. Predictors of Length of Stay and Patient Satisfaction after Hip and Knee Replacement Surgery: Fast-Track Experience in 712 Patients. Acta Orthop. 2008, 79, 168-173. [CrossRef] [PubMed]

7. Nuelle, D.G.; Mann, K. Minimal Incision Protocols for Anesthesia, Pain Management, and Physical Therapy with Standard Incisions in Hip and Knee Arthroplasties: The Effect on Early Outcomes. J. Arthroplast. 2007, 22, 20-25. [CrossRef]

8. Unlu, E.; Eksioglu, E.; Aydog, E.; Aydog, S.T.; Atay, G. The Effect of Exercise on Hip Muscle Strength, Gait Speed and Cadence in Patients with Total Hip Arthroplasty: A Randomized Controlled Study. Clin. Rehabil. 2007, 21, 706-711. [CrossRef] 
9. Gromov, K.; Kjaersgaard-Andersen, P.; Revald, P.; Kehlet, H.; Husted, H. Feasibility of Outpatient Total Hip and Knee Arthroplasty in Unselected Patients. Acta Orthop. 2017, 88, 516-521. [CrossRef] [PubMed]

10. Bodrogi, A.; Dervin, G.F.; Beaule, P.E. Management of Patients Undergoing Same-Day Discharge Primary Total Hip and Knee Arthroplasty. CMAJ 2020, 192, E34-E39. [CrossRef] [PubMed]

11. Aynardi, M.; Post, Z.; Ong, A.; Orozco, F.; Sukin, D.C. Outpatient Surgery as a Means of Cost Reduction in Total Hip Arthroplasty: A Case-Control Study. HSS J. 2014, 10, 252-255. [CrossRef]

12. Dorr, L.D.; Thomas, D.J.; Zhu, J.; Dastane, M.; Chao, L.; Long, W.T. Outpatient Total Hip Arthroplasty. J. Arthroplast. 2010, 25, 501-506. [CrossRef]

13. Lovecchio, F.; Alvi, H.; Sahota, S.; Beal, M.; Manning, D. Is Outpatient Arthroplasty as Safe as Fast-Track Inpatient Arthroplasty? A Propensity Score Matched Analysis. J. Arthroplast. 2016, 31, 197-201. [CrossRef]

14. Otero, J.E.; Gholson, J.J.; Pugely, A.J.; Gao, Y.; Bedard, N.A.; Callaghan, J.J. Length of Hospitalization After Joint Arthroplasty: Does Early Discharge Affect Complications and Readmission Rates? J. Arthroplast. 2016, 31, 2714-2725. [CrossRef]

15. Basques, B.A.; Tetreault, M.W.; Della Valle, C.J. Same-Day Discharge Compared with Inpatient Hospitalization Following Hip and Knee Arthroplasty. J. Bone Jt. Surg. Am. 2017, 99, 1969-1977. [CrossRef]

16. Courtney, P.M.; Boniello, A.J.; Berger, R.A. Complications Following Outpatient Total Joint Arthroplasty: An Analysis of a National Database. J. Arthroplast. 2017, 32, 1426-1430. [CrossRef] [PubMed]

17. Gromov, K.; Jorgensen, C.C.; Petersen, P.B.; Kjaersgaard-Andersen, P.; Revald, P.; Troelsen, A.; Kehlet, H.; Husted, H. Complications and Readmissions Following Outpatient Total Hip and Knee Arthroplasty: A Prospective 2-Center Study with Matched Controls. Acta Orthop. 2019, 90, 281-285. [CrossRef] [PubMed]

18. Berend, K.R.; Lombardi, A.V., Jr.; Berend, M.E.; Adams, J.B.; Morris, M.J. The Outpatient Total Hip Arthroplasty: A Paradigm Change. Bone Jt. J. 2018, 100, 31-35. [CrossRef] [PubMed]

19. Bovonratwet, P.; Webb, M.L.; Ondeck, N.T.; Lukasiewicz, A.M.; Cui, J.J.; McLynn, R.P.; Grauer, J.N. Definitional Differences of 'Outpatient' Versus 'Inpatient' THA and TKA Can Affect Study Outcomes. Clin. Orthop. Relat. Res. 2017, 475, $2917-2925$. [CrossRef]

20. Carey, K.; Morgan, J.R.; Lin, M.Y.; Kain, M.S.; Creevy, W.R. Patient Outcomes Following Total Joint Replacement Surgery: A Comparison of Hospitals and Ambulatory Surgery Centers. J. Arthroplast. 2020, 35, 7-11. [CrossRef]

21. Crampet, C.; Common, H.; Bajeux, E.; Bourgoin, A.; Thomazeau, H.; Polard, J.-L.; Orthopedics, Traumatology Society of Western France. Does Performing Outpatient Total Hip Arthroplasty Contribute to Early Complications and Readmissions? Retrospective Case-Control Study of 50 Patients. Orthop. Traumatol. Surg. Res. 2019, 105, 1245-1249. [CrossRef]

22. Goyal, N.; Chen, A.F.; Padgett, S.E.; Tan, T.L.; Kheir, M.M.; Hopper, R.H., Jr.; Hamilton, W.G.; Hozack, W.J. Otto Aufranc Award: A Multicenter, Randomized Study of Outpatient versus Inpatient Total Hip Arthroplasty. Clin. Orthop. Relat. Res. 2017, 475, 364-372. [CrossRef] [PubMed]

23. Greenky, M.R.; Wang, W.; Ponzio, D.Y.; Courtney, P.M. Total Hip Arthroplasty and the Medicare Inpatient-Only List: An Analysis of Complications in Medicare-Aged Patients Undergoing Outpatient Surgery. J. Arthroplast. 2019, 34, 1250-1254. [CrossRef]

24. Kelly, M.P.; Calkins, T.E.; Culvern, C.; Kogan, M.; Della Valle, C.J. Inpatient Versus Outpatient Hip and Knee Arthroplasty: Which Has Higher Patient Satisfaction? J. Arthroplast. 2018, 33, 3402-3406. [CrossRef] [PubMed]

25. Krenk, L.; Kehlet, H.; Baek Hansen, T.; Solgaard, S.; Soballe, K.; Rasmussen, L.S. Cognitive Dysfunction after Fast-Track Hip and Knee Replacement. Anesth. Analg. 2014, 118, 1034-1040. [CrossRef] [PubMed]

26. Nelson, S.J.; Webb, M.L.; Lukasiewicz, A.M.; Varthi, A.G.; Samuel, A.M.; Grauer, J.N. Is Outpatient Total Hip Arthroplasty Safe? J. Arthroplast. 2017, 32, 1439-1442. [CrossRef]

27. Richards, M.; Alyousif, H.; Kim, J.K.; Poitras, S.; Penning, J.; Beaule, P.E. An Evaluation of the Safety and Effectiveness of Total Hip Arthroplasty as an Outpatient Procedure: A Matched-Cohort Analysis. J. Arthroplast. 2018, 33, 3206-3210. [CrossRef]

28. Tedder, C.; DeBell, H.; Dix, D.; Smith, W.R.; McGwin, G., Jr.; Shah, A.; Naranje, S. Comparative Analysis of Short-Term Postoperative Complications in Outpatient Versus Inpatient Total Ankle Arthroplasty: A Database Study. J. Foot Ankle Surg. 2019, 58, 23-26. [CrossRef]

29. Weiser, M.C.; Kim, K.Y.; Anoushiravani, A.A.; Iorio, R.; Davidovitch, R.I. Outpatient Total Hip Arthroplasty Has Minimal Short-Term Complications with the Use of Institutional Protocols. J. Arthroplast. 2018, 33, 3502-3507. [CrossRef] [PubMed]

30. Ziemba-Davis, M.; Caccavallo, P.; Meneghini, R.M. Outpatient Joint Arthroplasty-Patient Selection: Update on the Outpatient Arthroplasty Risk Assessment Score. J. Arthroplast. 2019, 34, S40-S43. [CrossRef]

31. Page, M.J.; McKenzie, J.E.; Bossuyt, P.M.; Boutron, I.; Hoffmann, T.C.; Mulrow, C.D.; Shamseer, L.; Tetzlaff, J.M.; Akl, E.A.; Brennan, S.E.; et al. The PRISMA 2020 Statement: An Updated Guideline for Reporting Systematic Reviews. BMJ 2021, 372, n71. [CrossRef]

32. ASTM F2706-18 STMfO-CaO-C-TSICiaVM, ASTM International, West Conshohocken, PA. 2018. Available online: www.astm.org (accessed on 15 October 2020).

33. Coleman, B.D.; Khan, K.M.; Maffulli, N.; Cook, J.L.; Wark, J.D. Studies of Surgical Outcome after Patellar Tendinopathy: Clinical Significance of Methodological Deficiencies and Guidelines for Future Studies. Victorian Institute of Sport Tendon Study Group. Scand. J. Med. Sci. Sports 2000, 10, 2-11. [CrossRef] [PubMed] 
34. Bletterman, A.N.; de Geest-Vrolijk, M.E.; Vriezekolk, J.E.; Nijhuis-van der Sanden, M.W.; van Meeteren, N.L.; Hoogeboom, T.J. Preoperative Psychosocial Factors Predicting Patient's Functional Recovery after Total Knee or Total Hip Arthroplasty: A Systematic Review. Clin. Rehabil. 2018, 32, 512-525. [CrossRef] [PubMed]

35. Churchill, L.; Pollock, M.; Lebedeva, Y.; Pasic, N.; Bryant, D.; Howard, J.; Lanting, B.; Laliberte Rudman, D. Optimizing Outpatient Total Hip Arthroplasty: Perspectives of Key Stakeholders. Can. J. Surg. 2018, 61, 370-376. [CrossRef]

36. Zomar, B.O.; Marsh, J.D.; Lanting, B.A.; Bryant, D.M. A Protocol for a Randomized Controlled Trial Investigating the Safety and Cost-Effectiveness of Outpatient Total Hip Arthroplasty. BMC Musculoskelet. Disord. 2020, 21, 663. [CrossRef] [PubMed]

37. Arshi, A.; Leong, N.L.; Wang, C.; Buser, Z.; Wang, J.C.; SooHoo, N.F. Outpatient Total Hip Arthroplasty in the United States: A Population-based Comparative Analysis of Complication Rates. J. Am. Acad. Orthop. Surg. 2019, 27, 61-67. [CrossRef] [PubMed]

38. Xu, J.; Cao, J.Y.; Chaggar, G.S.; Negus, J.J. Comparison of Outpatient Versus Inpatient Total Hip and Knee Arthroplasty: A Systematic Review and Meta-Analysis of Complications. J. Orthop. 2020, 17, 38-43. [CrossRef]

39. Wolf, O.; Mattsson, P.; Milbrink, J.; Larsson, S.; Mallmin, H. The Effects of Different Weight-Bearing Regimes on Press-Fit Cup Stability: A Randomised Study with Five Years of Follow-Up Using Radiostereometry. Int. Orthop. 2012, 36, 735-740. [CrossRef] [PubMed]

40. Pollock, M.; Somerville, L.; Firth, A.; Lanting, B. Outpatient Total Hip Arthroplasty, Total Knee Arthroplasty and Unicompartmental Knee Arthroplasty: A Systematic Review of the Literature. JBJS Rev. 2016, 4. [CrossRef]

41. Haddad, S.L.; Coetzee, J.C.; Estok, R.; Fahrbach, K.; Banel, D.; Nalysnyk, L. Intermediate and Long-Term Outcomes of Total Ankle Arthroplasty and Ankle Arthrodesis. A Systematic Review of the Literature. J. Bone Jt. Surg. Am. 2007, 89, 1899-1905. [CrossRef]

42. Gonzalez, T.; Fisk, E.; Chiodo, C.; Smith, J.; Bluman, E.M. Economic Analysis and Patient Satisfaction Associated with Outpatient Total Ankle Arthroplasty. Foot Ankle Int. 2017, 38, 507-513. [CrossRef] [PubMed]

43. Pugely, A.J.; Martin, C.T.; Gao, Y.; Mendoza-Lattes, S.A. Outpatient Surgery Reduces Short-Term Complications in Lumbar Discectomy: An Analysis of 4310 Patients from the ACS-NSQIP Database. Spine 2013, 38, 264-271. [CrossRef] [PubMed]

44. Khuri, S.F.; Daley, J.; Henderson, W.; Hur, K.; Demakis, J.; Aust, J.B.; Chong, V.; Fabri, P.J.; Gibbs, J.O.; Grover, F.; et al. The Department of Veterans Affairs' NSQIP: The First National, Validated, Outcome-Based, Risk-Adjusted and Peer-Controlled Program for the Measurement and Enhancement of the Quality of Surgical Care. National VA Surgical Quality Improvement Program. Ann. Surg. 1998, 228, 491-507. [CrossRef]

45. Mulligan, R.P.; Parekh, S.G. Safety of Outpatient Total Ankle Arthroplasty vs Traditional Inpatient Admission or Overnight Observation. Foot Ankle Int. 2017, 38, 825-831. [CrossRef] [PubMed]

46. Bert, J.M.; Hooper, J.; Moen, S. Outpatient Total Joint Arthroplasty. Curr. Rev. Musculoskelet. Med. 2017, 10, 567-574. [CrossRef]

47. Jorgensen, C.C.; Kehlet, H.; Lundbeck Foundation Centre for Fast-track Hip; Knee Replacement Collaborative Group. Role of Patient Characteristics for Fast-Track Hip and Knee Arthroplasty. Br. J. Anaesth. 2013, 110, 972-980. [CrossRef] [PubMed]

48. Meneghini, R.M.; Ziemba-Davis, M.; Ishmael, M.K.; Kuzma, A.L.; Caccavallo, P. Safe Selection of Outpatient Joint Arthroplasty Patients with Medical Risk Stratification: The “Outpatient Arthroplasty Risk Assessment Score”. J. Arthroplast. 2017, 32, 2325-2331. [CrossRef] [PubMed]

49. Husted, H.; Otte, K.S.; Kristensen, B.B.; Orsnes, T.; Kehlet, H. Readmissions after Fast-Track Hip and Knee Arthroplasty. Arch. Orthop. Trauma Surg. 2010, 130, 1185-1191. [CrossRef]

50. Stambough, J.B.; Nunley, R.M.; Curry, M.C.; Steger-May, K.; Clohisy, J.C. Rapid Recovery Protocols for Primary Total Hip Arthroplasty Can Safely Reduce Length of Stay without Increasing Readmissions. J. Arthroplast. 2015, 30, 521-526. [CrossRef]

51. Springer, B.D.; Odum, S.M.; Vegari, D.N.; Mokris, J.G.; Beaver, W.B., Jr. Impact of Inpatient Versus Outpatient Total Joint Arthroplasty on 30-Day Hospital Readmission Rates and Unplanned Episodes of Care. Orthop. Clin. N. Am. 2016, 48, 15-23. [CrossRef]

52. Shapira, J.; Chen, S.L.; Rosinsky, P.J.; Maldonado, D.R.; Lall, A.C.; Domb, B.G. Outcomes of Outpatient Total Hip Arthroplasty: A Systematic Review. HIP Int. 2021, 31, 4-11. [CrossRef] [PubMed]

53. Schairer, W.W.; Sing, D.C.; Vail, T.P.; Bozic, K.J. Causes and Frequency of Unplanned Hospital Readmission after Total Hip Arthroplasty. Clin. Orthop. Relat. Res. 2014, 472, 464-470. [CrossRef]

54. de Vries, L.M.; Sturkenboom, M.C.; Verhaar, J.A.; Kingma, J.H.; Stricker, B.H. Complications after Hip Arthroplasty and the Association with Hospital Procedure Volume. Acta Orthop. 2011, 82, 545-552. [CrossRef] [PubMed]

55. Migliorini, F.; Eschweiler, J.; Trivellas, A.; Rath, B.; Driessen, A.; Tingart, M.; Arentini, P. Implant Positioning among the Surgical Approaches for Total Hip Arthroplasty: A Bayesian Network Meta-Analysis. Arch. Orthop. Trauma Surg. 2020, 140, 1115-1124. [CrossRef] [PubMed]

56. Migliorini, F.; Trivellas, A.; Eschweiler, J.; El Mansy, Y.; Mazzanti, M.C.; Tingart, M.; Aretini, P. Hospitalization Length, Surgical Duration and Blood Lost among the Approaches for Total Hip Arthroplasty: A Bayesian Network Meta-Analysis. Musculoskelet. Surg. 2020, 104, 257-266. [CrossRef]

57. Migliorini, F.; Trivellas, A.; Eschweiler, J.; Driessen, A.; Lessi, F.; Tingart, M.; Aretini, P. Nerve Palsy, Dislocation and Revision Rate among the Approaches for Total Hip Arthroplasty: A Bayesian Network Meta-Analysis. Musculoskelet. Surg. 2021, 105, 1-15. [CrossRef]

58. Migliorini, F.; Biagini, M.; Rath, B.; Meisen, N.; Tingart, M.; Eschweiler, J. Total Hip Arthroplasty: Minimally Invasive Surgery or Not? Meta-Analysis of Clinical Trials. Int. Orthop. 2019, 43, 1573-1582. [CrossRef] 
59. Bennett, D.; Ogonda, L.; Elliott, D.; Humphreys, L.; Lawlor, M.; Beverland, D. Comparison of Immediate Postoperative Walking Ability in Patients Receiving Minimally Invasive and Standard-Incision Hip Arthroplasty: A Prospective Blinded Study. J. Arthroplast. 2007, 22, 490-495. [CrossRef]

60. Migliorini, F.; Driessen, A.; Colarossi, G.; El Mansy, Y.; Gatz, M.; Tingart, M.; Eschweiler, J. Short Stems for Total Hip Replacement among Middle-Aged Patients. Int. Orthop. 2020, 44, 847-855. [CrossRef]

61. Graves, S.C.; Dropkin, B.M.; Keeney, B.J.; Lurie, J.D.; Tomek, I.M. Does Surgical Approach Affect Patient-reported Function After Primary THA? Clin. Orthop. Relat. Res. 2016, 474, 971-981. [CrossRef] [PubMed]

62. Talia, A.J.; Coetzee, C.; Tirosh, O.; Tran, P. Comparison of Outcome Measures and Complication Rates Following Three Different Approaches for Primary Total Hip Arthroplasty: A Pragmatic Randomised Controlled Trial. Trials 2018, 19, 13. [CrossRef] [PubMed]

63. Panichkul, P.; Bavonratanavech, S.; Arirachakaran, A.; Kongtharvonskul, J. Comparative Outcomes between Collared Versus Collarless and Short Versus Long Stem of Direct Anterior Approach Total Hip Arthroplasty: A Systematic Review and Indirect Meta-Analysis. Eur. J. Orthop. Surg. Traumatol. 2019, 29, 1693-1704. [CrossRef] [PubMed] 